\title{
Ubiquitous Health in Korea: Progress, Barriers, and Prospects
}

\author{
Yountae Lee, $\mathrm{PhD}^{1}$, Hyejung Chang, $\mathrm{PhD}^{2}$ \\ ${ }^{1}$ Korea Health Industry Development Institute, Cheongwon; ${ }^{2}$ School of Management, Kyung Hee University, Seoul, Korea
}

Objectives: Korea has one of the most advanced information technology (IT) infrastructures in the world, and the application of IT in health systems is rapidly progressing from computerization to information systems, ubiquitous systems, and smart systems. This study aims to analyze Korean environments in regards to the development of their u-Health industry and propose directions for u-Healthcare services based on this analysis. Methods: This paper reviews the background, progress history, and current status of $\mathrm{u}$-Health in Korea, and suggests strategies for the u-Health industry based on an analysis of its barriers and obstacles. Results: When u-Health was introduced to Koreans, their policies and approaches focused mainly on environmental factors, yet these efforts have not progressed further to impact the u-Healthcare service industry itself. To develop the u-Healthcare industry, four points need to be considered: the development and support of the practical service model, institutional support, support of core technology and industry, and the institutionalization of health management service. Conclusions: Korea is at a strategic point to start building u-Healthcare service delivery models. u-Healthcare is a healthcare service that provides added value through u-Health environments. By identifying critical success factors in uHealthcare, we can strengthen the u-Health industry and implement policies to coordinate our efforts in the process of value chains to which we belong.

Keywords: Mobile Health, Telecommunications, Wireless Technology, Health Information Management, Consumer Health Information

Submitted: December 17, 2012

Revised: December 31, 2012

Accepted: December 31, 2012

\section{Corresponding Author}

Hyejung Chang, PhD

School of Management, Kyung Hee University, 26 Kyungheedae-ro, Dongdaemun-gu, Seoul 130-701, Korea. Tel: +82-2-961-9432, Fax: +82-2-961-0515, E-mail: hjchang@khu.ac.kr

This is an Open Access article distributed under the terms of the Creative Commons Attribution Non-Commercial License (http://creativecommons.org/licenses/by$\mathrm{nc} / 3.0 /$ ) which permits unrestricted non-commercial use, distribution, and reproduction in any medium, provided the original work is properly cited.

(C) 2012 The Korean Society of Medical Informatics

\section{Introduction}

The life expectancy of the Korean population has increased from 52.4 years in 1960, to 63.3 in 1970, 65.8 in 1980, 71.6 in 1990, 75.9 in 2000, 80.8 in 2010, and 81.2 in 2011 [1]. However, this increase in life expectancy does not entail an increase in health life expectancy, the expectancy of how long people can live without any physical or psychological impediments. For example, the expected life expectancy of those who were born in 2009 is 80.67 years, but their health life expectancy is estimated at 72.63 , after which many will experience a significant degradation of health; those born 
in 2009 will spend approximately 8.04 years (approximately $10 \%)$ of their lives in an unhealthy state [2].

The issues of an aging society and a prolonged life expectancy lead to increasing medical expenditures for the society. Specifically, the ratio of the Korean healthcare expenditure to gross domestic product (GDP) was approximately $7.2 \%$ in 2009, which was lower than the average of the other Organisation for Economic Co-operation and Development (OECD) nations, which was 9.5\% [3,4]. The growth of per capita annual healthcare expenditures in Korea during 20002009, however, was $7.7 \%$, which was more than double the average of the expenditure (3.6\%) of other OECD nations $[3,4]$. It is expected that this unprecedented phenomenon of a rapidly aging society will result in a drastic increase in chronic diseases and an expansion of national medical care expenditures as health insurance becomes mandatory.

Therefore, it is necessary to devise approaches to control the rapid growth and inefficient use of national healthcare resources. Fortunately, Korea has one of the most advanced information technology (IT) infrastructures in the world, and with the convergence of information technologies, Korea is an ideal environment for ubiquitous connection $[5,6]$. The application of IT in health systems is rapidly progressing from computerization to information systems, ubiquitous systems, and smart systems.

The development of information systems for health services is becoming one of the most important priorities on the national agenda as IT and health technologies become integrated and patients enjoy better quality health services and significant cost savings for those services [7]. Hospitals in Korea are increasingly adopting healthcare IT to remain competitive, and as a result, the information systems in the healthcare industry are rapidly progressing to ubiquitous health (u-Health) through e-Health [8].

Specifically, information systems in hospitals are now capable of telemedicine in addition to digitization of patient information, digital storage of picture images, and computerization of hospital administration, and some hospitals acquire patient data and maintain continuous patient contacts using sensor technology and ubiquitous systems [9]. In other words, the u-Health initiative entails the continuous monitoring of patient information even outside of the hospital setting. $\mathrm{u}$-Healthcare is a new form of service intended to help administer health care and management for the public by overcoming time and geographical constraints.

At the same time, however, the use of $\mathrm{u}$-healthcare brings up ethical issues, such as issues dealing with trust, privacy and liability, and the use of computers in medical environments $[10,11]$. In addition, national $\mathrm{u}$-Health service was not able to realize significant market potential due to outdated laws, an undeveloped insurance fee schedule, an inappropriate level of technical standardization, a shortage of professional workforce, insufficient data on basic statistics, and a non-existence of business models. [12]. Therefore, this study aims to analyze Korean environments in their development of the u-Health industry and propose directions for $\mathrm{u}$-Healthcare services based on this analysis.

\section{What is u-Health?}

\section{Locus of u-Health}

$\mathrm{u}$-Health focuses on ubiquitous computing applications that can provide healthcare to people anywhere and anytime using broadband and wireless mobile technologies [13]. The terminology used to describe the notion of ubiquitous computing varied over time and in different literature [14]. Lyytinen and Yoo [15] categorize these types of computing depending on the levels of mobility and embeddedness. Devices with high level of embeddedness are called pervasive devices, and pervasive devices can exchange information with their environment. This imposes serious constraints on the level of mobility of such devices, which can be surmounted with further technological advances. Mobile computing, on the other hand, provides a high level of mobility with a computing model being approximately independent from context.

Along with this framework, the concept of $\mathrm{u}$-Health also involves two dimensions. With mobility characteristics, e-Health evolves to mobile health (m-Health), and with embeddedness, e-Health evolves to pervasive health (p-Health).

Level of mobility

Low

High

\begin{tabular}{|c|c|c|}
\hline Low & $\begin{array}{l}\text { Conventional e-Health } \\
\text { Traditional electronic computing }\end{array}$ & $\begin{array}{l}\text { m-Health } \\
\text { Mobile computing }\end{array}$ \\
\hline ddedness & $\begin{array}{c}\text { p-Health } \\
\text { Pervasive computing }\end{array}$ & $\begin{array}{l}\text { u-Health } \\
\text { Ubiquitous computing }\end{array}$ \\
\hline
\end{tabular}

Figure 1. Locus of u-Health. 
u-Health covers all concepts of e-Health, m-Health, and p-Health with both mobility and embeddedness characteristics, as shown in Figure 1.

\section{Definition of $u$-Health and $u$-Healthcare}

$\mathrm{u}$-Health is a broad concept that consists of $\mathrm{u}$-Healthcare and $\mathrm{u}$-Health environments. $\mathrm{u}$-Healthcare is a value-added health service that was realized through the establishment of $\mathrm{u}$-Health environments, and $\mathrm{u}$-Health environments are health environments where the organization and networking of healthcare resources become possible through ubiquitous computing technology [16].

Therefore, $\mathrm{u}$-Healthcare is a combination of healthcare and ubiquitous computing. Healthcare is a service that provides prevention, diagnosis, treatment, and management of illness and also preserves mental and physical well-being through healthcare resources [17], components of which are facilities, manpower, equipment, information, and knowledge to make the service possible. Ubiquitous computing is an integration of computing, wireless networking, and sensor technology, and it allows users to store and process the information using a network capability and equipment that includes a processor and sensor [18]. Therefore, u-Healthcare can be defined as added value to an existing medical health service that integrates the core characteristics of ubiquitous com- puting in the process of delivering healthcare resources and services.

One of prime examples of added value is the expansion of time and space limits of healthcare service delivery. The measurement of bio-signals in real-time using mobile devices has expanded the time span of service which was once limited by the running time of existing healthcare service provision. It also addressed the space limitations of face-toface diagnosis by using diagnosis and consultation via telemedicine.

Another example of added value is the revision of individually customized service. The integration and networking of healthcare resources has enabled the convergence of patient information on their treatment, bio-data, and genetics, and also the pattern-mining of vast amount of health information database. In order to create a consumer-oriented service, which is the aim of ubiquitous industry, healthcare practice needs to be supported by the optimal decision-making process based on individual characteristics and circumstances.

To summarize, e-Health utilizes information systems by merely applying them to existing healthcare practices to improve the productivity of the work of the health service provider, and $\mathrm{u}$-Health aims to innovate healthcare services rendered by utilizing the basic characteristics of ubiquitous computing to address the expanding time and space require-

Table 1. Classification of u-Health environment

\begin{tabular}{|c|c|}
\hline Class & Example component \\
\hline \multirow[t]{8}{*}{ Clinical-technology environment } & Electronic Health Record (EHR) \\
\hline & Clinical decision supporting system (CDSS) \\
\hline & Pattern-mining based clinical practice guideline (CPG) \\
\hline & Platform and standard interface integrating $\mathrm{u}$-Healthcare services \\
\hline & $\begin{array}{l}\text { Ubiquitous sensor network (USN)-based bio-signal sensing, manipulation, analysis, storage, } \\
\text { and communication }\end{array}$ \\
\hline & Medical image retrieval, archival compression, search communication \\
\hline & $\begin{array}{l}\text { Radio-frequency identification (RFID)-based hospital information system: smartcard, } \\
\text { pharmaceutical supply chain management, patient management, hospital management }\end{array}$ \\
\hline & $\begin{array}{l}\text { Clinical-bio-information convergence technology: intelligent patient safety technology, } \\
\text { disease prediction technology, clinical prediction bio-marker }\end{array}$ \\
\hline \multirow[t]{3}{*}{ Regulatory environment } & u-Health Special Act \\
\hline & u-Health standardization system \\
\hline & u-Health certification system \\
\hline \multirow[t]{3}{*}{ Socio-cultural environment } & $\begin{array}{l}\text { Education and training system for } \mathrm{u} \text {-Health experts: converged training and interdisciplinary } \\
\text { education programs }\end{array}$ \\
\hline & Supporting system for u-Health industry \\
\hline & Consumers' perception and acceptance to u-Health services: marketing, advertisement \\
\hline
\end{tabular}


ments. Ultimately, u-Health reflects a paradigm shift towards an orientation toward the consumer by providing a customized healthcare service which is accessible anytime and anywhere, based on the core characteristics and capabilities offered by ubiquitous computing.

In order for consumers to enjoy the new convenience and added values of healthcare service offered by $\mathrm{u}$-Health, a new ubiquitous computing environment should be first introduced to the existing healthcare service environment. In reality, the main reasons for the hindrance to u-Healthcare services are external factors, such as a lack of relevant legal support, limitation of standard practice, a lack of standardization, a lack of industry infrastructure, and a low societal and cultural receptivity. u-Health environments include not only the technology, but also other factors that help realize $\mathrm{u}$-Health, such as institutions and social and cultural recognition (Table 1).

\section{3. u-Health as a Convergence Perspective}

The healthcare industry is progressing toward convergence. In the agricultural era, medical practice was based on experience (experiential medicine), and education was provided through apprenticeship and experiential learning. In the industrial era, medical practice was based on medical equipment (equipment medicine), and the service was provided using treatment equipment using technologies in radiation, clinical pathology, and ultrasound. In the information era, the medical practice became based on IT, and the emphasis shifted to improving the efficiency of hospital administration and digitizing and integrating the information within and among hospitals (e-Health). Lastly, the ubiquitous era integrates the healthcare resources with IT, connecting all the healthcare resources through wired and wireless networks, thus connecting and networking people to people, people to equipment, and equipment to equipment (u-Health) [19].

The convergence era provides a healthcare service that makes it possible to combine biotechnology (BT) in order to create or transform a form of human life by using ubiquitous computing, genetic engineering, and nanotechnology (NT) to handle minute material on an atomic or molecular level (convergence medicine). The convergence of IT, BT, and NT technologies is characterized by the departure of an unpredictable future from the past and allows for the transformation of healthcare service from disease treatment to pre-diagnosis and preventive medicine, and we expect a dramatic increase in customized treatment using genetic code information.

The main application of this technology convergence to the $\mathrm{u}$-Health environment will be in the areas of development of intelligent patient safety technology and clinical treatment technology based on data/pattern mining of clinical, biomedical, and biological information, and the development of technology for early diagnosis, disease prediction and prevention, and general health promotion program based on the convergence of bio-genetic and clinical information of patients. The existing healthcare service will evolve into future healthcare environments including advanced delivery system of healthcare service, preventive medicine, life-long management and treatment, and delivery of customized service.

\section{Progress of u-Health}

\section{Emergence of a Ubiquitous System in Korea}

The term "ubiquitous" appeared first in Korea in 2002 when the Korea Electronics Telecommunications Research Institute (ETRI) translated and published the Japanese study "Information and Telecommunication Technology in 2015," originally published by the Nippon Telegraph and Telephone (NTT) Technology Forecast Research Team [20]. This study indicated that the future of IT technology and service was the ubiquitous system. After that, the Korean Electronic Times introduced the "ubiquitous" concept in its special edition by describing it as a system to connect people, computers, and objects so that information is freely exchanged among them in a space without any constraints.

In 2003, the Ministry of Information and Communication announced a new policy to stimulate and revitalize ubiquitous industry among government agencies, including 'Build u-Korea Project' and 'Ubiquitous Oriented Appliance Solutions Technology Development Project.' From that time on, significant investment has been made in the areas of core technology such as wireless network, smart network, networking middleware, applications platform, and the development of application solutions in service, contents, and commerce, among which the healthcare application was considered one of the main application solutions using the ubiquitous concept.

A national health information solution company started to use the word "Ubiquitous Healthcare", and in the same year Samsung followed suit by designating u-Health as a key growth industry. Many large-scale communications and electronics companies joined the government-led ubiquitous projects, and they started to apply the ubiquitous healthcare concept in wired and wireless health management systems as part of their pilot projects.

At the same time, the academic society and independent institutes started to publish on the u-Health industry-its 
market potential, business models for it, and analyses of its demand-and some university institutes started to focus on related subjects such as that of the biosensor. As healthcare service merged with IT, the e-Health paradigm based on the hospital information system began to switch over to $\mathrm{u}$-Health paradigm. For example, in the proceeding of the u-Health industry workshop in 2005, we see the concepts of e-Health and u-Health being interchangeably used based on the understanding level and different perspectives of presenters [19].

When the concept of $\mathrm{u}$-Health was introduced, the information and telecommunication industry identified $\mathrm{u}$-Health as one area in which they could build new business beyond the existing IT markets and made rigorous investments in its R\&D with the hopes of gaining entry into the growing healthcare market. This interest continued to expand among information solution providers, computer vendors, home network businesses, and construction companies involved in government projects on u-City [21].

\section{Directions of Government Policy}

Before 2008, u-Health-related policies and projects were independently pursued by the government-specifically, the Ministry of Information and Communication, the Ministry of Commerce, Industry and Energy, and the Ministry of Health and Welfare. The Government also established the Medical Industry Advancement Committee directly under the President's Office during 2005 and 2007 in order to advance the healthcare industry and improve the health care provision system, and they had the u-Health issues reviewed and evaluated by the Committee on Improving the Healthcare Service Systems.

The Ministry of Information and Communication listed uHealth under the home network industry as part of nine new strategic growth industries and its IT839 strategy and promoted the development of these industries in order to create convenience, stability, and economic success for homes through a high speed telecommunications network which has been already established [22]. However, its emphasis has been more on establishing infrastructure for digital homes, and not on building a foundation for the u-Healthcare system.

The Ministry of Commerce, Industry and Energy has also selected 40 growth areas of business, among which five are $\mathrm{u}$-Health-related businesses. The Ministry is also in the process of building the 'e-Health Network' in conjunction with other related agencies to commercialize the next generation health-phones for the public.

The policies of the Ministry of Health and Welfare can be divided into two eras: before 2008 and after. Its policies before 2008 centered around building the e-Health structure including the standardization of Electronic Health Records (EHR) and the organization of public health information, running some pilot projects in cooperation with other agencies by providing matching funds. After 2008, it made conscious efforts to initiate $\mathrm{u}$-Health related projects. It realized that the existing $\mathrm{u}$-Health related projects were implemented without any focus and coordination among multiple agencies, and it strived to develop a collaborative model to draw reasonable cooperation from public and private institutions, state and municipal organizations, and government agencies.

For this purpose, the Ministry of Health and Welfare first established a comprehensive plan for " $\mathrm{u}$-Healthcare Revitalization," and second, developed a plan to initiate and improve collaborative pilot projects working with other agencies, and third, tried to establish support and build infrastructure for the R\&D of u-Health-related core skills, and fourth, developed and implemented plans for facilitating the industrialization and developing cooperative relationships between public and private agencies for marketing them abroad [23].

\section{Trends of u-Health Service}

Currently, efforts to revitalize the u-Health industry and invest in developing skills and infrastructure did not meet the market expansion expectations of entrepreneurial business people. Many pilot projects were concluded before they were commercialized for the public market.

One of the main reasons for this debacle is that the delivery systems of service models proposed by industry leaders have not been permitted by the current laws and regulations. For this reason, there has not been any significant commercial service model except for the off-site consultation model established long after the concept of $\mathrm{u}$-Healthcare was introduced to the nation. The recent pilot projects initiated by the Ministry of Health and Welfare in the u-Healthcare category based on ubiquitous sensor network (USN) [24] and the smart care pilot projects implemented by the Ministry of Knowledge and Economy are attempts to find service models which are community-friendly and easy to commercialize and to reinforce recognition and reception of $\mathrm{u}$-Healthcare systems.

\section{Trends of u-Health Core Skills}

The levels of core skills and technology of Korean u-Health system providers are low compared against other models in developed countries. Korea's technical level of sensor technologies lags two years behind compared against the level of 
advanced countries. The software skills that analyze and convert collected data into standard format information is also insufficient and thus hinder producing respectable u-Health products [25].

In addition, there has not been much interchangeability among different products that were developed by multiple vendors, and this is causing problems in developing the $\mathrm{u}$ Health industry. In order to address this situation, there is an active movement to ensure interchangeability among healthcare products using international standards such as ISO/ IEEE 11073 personal health data (PHD) and Health Level Seven International (HL7) Clinical Document Architecture (CDA) [26].

\section{Institutional Situations}

The reasons for the failure of the commercialization of the product in spite of intensive efforts by various business enterprises include the exclusivity of healthcare service delivery systems, the limited number of its service objects and methods, and the low level of trust from the suppliers in the u-Health system. The industry stakeholders point to institutional regulations as the main reasons for the stunted growth of the u-Health industry, and they urgently request the revision of related laws and regulations to accommodate new opportunities in u-healthcare [19].

\section{Industry Perspective}

The introduction and interest in $\mathrm{u}$-Health started from outside healthcare industries. u-Health is an integration of healthcare and IT but was presented to the healthcare service providers when they were not ready to realize the need for it. Since there has been no sufficient evidence of its safety and validity, it might be difficult to expect immediate application of this concept in the healthcare field, which traditionally believed in and practiced the evidence-based methodology.

However, interest in u-Health has been rising as multiple study reports have been published on the market potential and on its technology development, and as medical experts participate in its pilot projects and propose ways to make technical improvements [25]. In a recent nationwide survey of 300 medical doctors who work in healthcare institutions, $90 \%$ of respondents replied that u-Health will play an important role in overall or partial healthcare industry as they evolve into future medicine [27].

In order for u-Health to be established as one of the future approaches of healthcare service delivery, healthcare professionals indicated that they need to experience and accumulate clinical and academic knowhow of u-Health and that they need to be prepared to discuss the role of definitions of primary, secondary, and tertiary healthcare institutions before they provide the service to patients [23]. It was also pointed out that unclear accountability of legal responsibility in case of medical errors, low commitment to health insurance fees, and the leakage of patients' private information can pose serious problems in implementing the $\mathrm{u}$-Healthcare services.

\section{Barriers to u-Health}

\section{Regulatory Barrier}

Even though the government and private sectors are working together to promote $\mathrm{u}$-Health, the biggest stumbling block is institutional regulations. The Korean government has made a decision to allow u-Health service in areas in which there is limited access to medical facilities and the patient has been treated before, but this decision has not been fully implemented due to regulatory barriers such as the problems associated with medical insurance support, medical fees, and responsibility for medical accidents. This limitation comes mainly from the service provider entrenched on existing laws and regulations, and it needs to be addressed from the perspective of the patients as soon as possible.

\section{Security, Privacy, and Confidentiality}

In the context of $\mathrm{u}$-Health, a person no longer has any privacy due to the persistent recording of health-related information even outside of the hospital setting, but the rationale behind u-Health seems to be more pragmatic and benevolent. In $\mathrm{u}$-Health system, there can be greater exposure to security than traditional systems if the system is not ready to deal with and try to prevent dysfunctions of information systems. If sensitive private information is not properly managed and protected, there can be an infringement on privacy, which will have dire effects on peoples' lives. Telemedicine and cyber hospitals have weaknesses when it comes to protecting confidential information and the security of patients because of the openness and vulnerability of wireless communication systems. In addition, if there are weak links in the authority and accountability chains of a hospital's administration systems, there is always a possibility that the patients' information can leak through the internal staff.

\section{Shortages of Professional Health IT Workforce}

Even with a growing industry, though, Korea faces shortages in terms of human resources. The healthcare IT industry is said to be lacking in capable professionals who can develop the required systems for EHR and u-Health. A workforce capable of innovating, implementing, and using health com- 
munications and information technologies will be critical to healthcare's success. Health service providers do need to establish their role in the whole healthcare IT environment [28]. The aim is for healthcare IT to complement the health service provider's work and enhance workflow rather than hinder it. For successful industry transformation to uHealth, healthcare IT workforce needs homo-convergence with healthcare knowledge and technology expertise. The most important step is to provide educational curricula and learning environments that fully reflect the electronic environment in which health professionals will practice. The Korean government is also trying to recruit foreign talent, as well as pushing IT-related programs in its local universities, to help address this shortage [29].

\section{Low Consumer Awareness}

Although technology is ubiquitous in healthcare, its impact on people's perceptions and lives is poorly understood [30]. When the Korea Institute for Industrial Economics and Trade surveyed the awareness level of $\mathrm{u}$-Health service with its users, it showed that the general public is not accustomed to u-Health [27]. The recognition level of telemedicine service $(33.8 \%)$ and telehealth management service $(27.2 \%)$ was low, and their participation rate was also low: telemedicine, $29.2 \%$ and telehealth management, 26.8\%. Many respondents also stated that they will consider using the u-Health service 5 years after it is fully implemented: telemedicine, $62.4 \%$ and telehealth management, $64.2 \%$. This indicates that the technological and clinical stability plays a very important role in determining the use of this service.

\section{Prospects of u-Healthcare}

When u-Health was first introduced in Korea, the policies announced and implemented regarding this subject were intended to establish and revitalize the environmental factors of $\mathrm{u}$-Health, and the approach in service facilitation also focused mainly on environmental factors. These efforts have not progressed further to impact the revitalization of the $\mathrm{u}$ Healthcare service industry itself.

In order for the u-Healthcare system to be established and revitalized in the market, there should be a firm foundation for practical services to be fully provided on site. The benefits of healthcare service which will be created by $\mathrm{u}$-Healthcare should be evident and able to justify the necessity of its own revitalization and appropriate policy implementation. An effective policy to induce the potential of $\mathrm{u}$-Healthcare is to develop a commercially viable service model. After a commercially viable service model is developed, we can provide institutional, technological, and industrial foundation to support the service model so that it can thrive and multiply. The following four points indicate the policy direction for the revitalization of $\mathrm{u}$-Healthcare: the development and support of a practical service model, institutional support, support of core technology and industry growth, and the institutionalization of health management service.

\section{Development and Support of a Practical Service Model} In order for u-Healthcare to become a practical service model in healthcare markets, it should secure medical safety and effectiveness in order to gain respect in the evidencebased medical field, and convince the service providers of their need to apply this practical technology in their service. We should devise ways to facilitate timely access and provide economic means for them to apply this to their service and for patients to use this with ease in order to establish the service that has been developed and introduced. The factors that need to be considered in each criterion are shown in Table 2 [19].

\section{Institutional Support}

In order for the service to be practical and established in the market, there should be an improvement in institutional matters in the following areas: limits to applying $\mathrm{u}$-Healthcare, clear accountability in preparation for $\mathrm{u}-\mathrm{Health}$ related accidents, and protection of individual health information.

Table 2. Model for practical u-Health services

\begin{tabular}{lll}
\hline & Criterion & \multicolumn{1}{c}{ Factors } \\
\hline Clinical feasibility & & Safety, efficacy, medical need \\
Economic feasibility & Healthcare provider & Applicability: utilization of device, regulatory restriction \\
& Patient/consumer & Geographic convenience, ease of use \\
Economic feasibility & Healthcare provider & Development, operation and maintenance costs \\
& Patient/consumer & Time and transportation costs \\
& Government & Healthcare expenditures \\
\hline
\end{tabular}


The institutional periphery of service practice should be designed in consideration of practical models that are being developed and the level of urgency and needs of the patients, so that it can be flexible and expand gradually as the needs arise. One of the biggest stumbling blocks to applying $\mathrm{u}-$ Healthcare is the lack of clarity in accountability in the case of medical errors. In current medical law, there is clear accountability described for cases where the local healthcare service provider is a medical doctor (physician, dentist, oriental doctor) and where he or she is not a medical doctor (Medical Laws, Article 34).

Based on the characteristics of $\mathrm{u}$-Healthcare, the accuracy of information can decrease compared to the accuracy of information gained in face to face contacts, and since it is more prone to errors than normal services due to equipment and communication failure, it is very important that technical stability and institutional foundation be provided and that the locus of responsibility be determined in preparation for future potential conflicts.

Since the protection of private information and private life is not guaranteed by the law as of yet, the periphery of service application based on private health information cannot be determined clearly, and it causes unnecessary concern to potential service beneficiaries, resulting in less participation in the service program. Private medical information is protected by constitutional laws, but the health information which is stored in a database could be pulled out and abused indiscriminately by a large number of researchers or staff, which could become a serious violation of privacy. Therefore, it is necessary to establish a legal process to prevent a misuse or abuse of private health information.

\section{Development of Core Technology and Support of In- dustry Promotion}

The core technology related to u-Healthcare can be used to enhance the practicality of technologies already developed when considered in conjunction with other commercial service models which have been already developed. Plans need to be developed to identify and support the companies that have the core technologies needed in proposed service models. As we prioritize the introduction processes of new service models, we could make focused and effective investments in the technologies that need further development. Table 3 suggests specific strategies to establish the founda-

Table 3. Strategies for infrastructure of u-Healthcare industry

\begin{tabular}{|c|c|}
\hline Classification & Strategies \\
\hline \multirow[t]{5}{*}{ Training and education of $\mathrm{u}$-Health workforce } & Raising professional and specialized healthcare IT workforce \\
\hline & Establishing industry-based practical educational programs \\
\hline & Prerequisites being biosensor engineering, bio-signal processing, and medical \\
\hline & information systems \\
\hline & Needs master-level educational qualification \\
\hline \multirow[t]{10}{*}{ Standardization and certification } & Intensive developmental program of professionals based on $\mathrm{u}$-Healthcare \\
\hline & standards through the active participation in foreign accreditation \\
\hline & organizations or agencies \\
\hline & Needs to form international networks of industry, academics, and research \\
\hline & institutes \\
\hline & Establishment of an agency responsible for standardization \\
\hline & Setting direction for standardization, selecting the targets of standardization, \\
\hline & and establishing the priority \\
\hline & Establishment of system to promote and implement standardization based on \\
\hline & the national contexts \\
\hline \multirow[t]{3}{*}{ Support for potential firms } & Establishment of administrative supporting system \\
\hline & Raising professional managerial staff \\
\hline & Increasing consulting support for technology transfer \\
\hline \multirow[t]{2}{*}{ International collaboration } & $\begin{array}{l}\text { Support participation in conference abroad, hosting of international academic } \\
\text { symposium }\end{array}$ \\
\hline & Establishment of consulting center abroad \\
\hline
\end{tabular}


tion to develop and promote the u-Healthcare industry.

\section{Institutionalization of Health Management Service}

Healthcare fields can be categorized into two areas: medical service and health service. u-Healthcare in the medical service area enhances the accessibility, efficiency, and effectiveness of the existing face-to-face contacts and serves in a complementary role as the industry proceeds to future medical practices. u-Healthcare to health management will stimulate the creation and expansion of new service markets and will be a core member of market growth in the future [31].

The area of health management service, however, is not institutionalized even in an off-line setting. One problem arises out of this situation: if some experts provide service, it can be categorized as an illegal act because of a lack of legal grounds, and therefore we cannot expect continued improvement in the quality of the service being rendered. Against this background, there is an effort to institutionalize the health management service, and various opinions and options from diverse groups should be considered and evaluated on a continuing basis.

\section{Conclusion}

$\mathrm{u}$-Healthcare is a healthcare service that provides added value through u-Health environments. Therefore, all participants in the u-Health industry and related staff are ultimately involved in the value chain to create a new healthcare service called u-Healthcare. After the u-Health was introduced in the Korean market, the Ministry of Health and Welfare and other government agencies initiated many u-Health projects, mainly focusing on creating foundational componentssuch as core technologies, standardization, communications, equipment-that consist $\mathrm{u}$-Health environments rather than $\mathrm{u}$-Healthcare itself and made impressive technological progress in each area. However, we are at a strategic point at which we should start building u-Healthcare service delivery models. By identifying and connecting core factors needed in u-Healthcare, we will be able to establish u-Health industry and implement plans and policies to coordinate each participant's efforts to the process in the value chains to which we belong.

\section{Conflict of Interest}

No potential conflict of interest relevant to this article was reported.

\section{References}

1. National Statistics Office (NSO). Life expectancy at birth [Internet]. Seoul, Korea: NSO; c2012 [cited at 2012 Dec 5]. Available from: http://www.index.go.kr/egams/stts/ jsp/potal/stts/PO_STTS_IdxMain.jsp?idx_cd=2758.

2. Chung YH. The life expectancy and health-adjusted life expectancy of Koreans. Health Welf Forum 2012;11:5-18.

3. Jeong HS, Shin JW. Trends in scale and structure of Korea's health expenditure over last three decades (19802009): financing, functions and providers. J Korean Med Sci 2012;27 Suppl:S13-20.

4. Organisation for Economic Co-operation and Development (OECD). Health at a glance 2011: OECD indicators. Paris: OECD Publishing; 2011.

5. The International Telecommunication Union. South Korea is named the world's most advanced IT economy [Internet]. Bangalore, India: Knoema; c2012 [cited at 2012 Oct 12]. Available from: http://www.itdirection. net/it-news-0012/101212-00296-it-news.shtml.

6. National Information Society Agency (NIA). Informatization in Korean society: digital society development of Korea. Seoul, Korea: NIA; 2011. p. 5-11.

7. Johnston B, Wheeler L, Deuser J, Sousa KH. Outcomes of the Kaiser Permanente Tele-Home Health Research Project. Arch Fam Med 2000;9(1):40-5.

8. Song TM, Lee SY, Lee KH, Park DS, Jin DL, Ryu SW, et al. u-Health: current status and tasks ahead. Seoul, Korea: Korea Institute for Health and Social Affairs; 2011. p. 23-34.

9. Akyildiz IF, Melodia T, Chowdhury KR. Wireless multimedia sensor networks: applications and testbeds. Proc IEEE 2008;96(10):1588-605.

10. Brown I, Adams AA. The ethical challenges of ubiquitous healthcare. Int Rev Inf Ethics 2007;8:53-60.

11. Anderson JG. Social, ethical and legal barriers to ehealth. Int J Med Inform 2007;76(5-6):480-3.

12. Lee YT, Kim SY. Policy development for u-Healthcare in Korea. Seoul, Korea: Korea Health Industry Development Institute; 2008. p. 78-99.

13. Kang SW, Lee SH, Koh YS. Emergence of u-Health era. CEO Inf 2007;(602):1-4.

14. Scholtz J. Ubiquitous computing goes mobile. ACM SIGMOBILE Mob Comput Commun Rev 2001;5(3):32-8.

15. Lyytinen K, Yoo Y. Issues and challenges in ubiquitous computing. Commun ACM 2001;45(12):63-5.

16. Lee YT, Kim SY. Policy development for u-Healthcare in Korea. Seoul, Korea: Korea Health Industry Development Institute; 2008. p. 18-23. 
17. American Heritage Medical Dictionary. Health care or healthcare [Internet]. Boston (MA): Houghton Mifflin Co.; c2007 [cited at 2012 Dec 5]. Available from: http:// medical-dictionary.thefreedictionary.com/health+care.

18. Trivedi P, Sagar KK, Vernon. Emerging trends of ubiquitous computing. Int J Adv Comput Sci Appl 2010;1(3): 72-4.

19. Lee YT, Kim MS, Kim SH, Kim SY, Park DK, Park SB, et al. Policy development for u-Healthcare in Korea. Seoul, Korea: Korea Health Industry Development Institute; 2010. p. 62-93.

20. Chun HW, Cho WJ. A study on new service models in ubiquitous era. Electron Commun Trends 2004;19(6): 169-80.

21. Lee YR, Lee HH. Market analysis of u-Health services and values. Seoul, Korea: National Information Society Agency; 2007. p. 17-46.

22. Ministry of Information and Communication. 2004 Annual report on electronics and telecommunications [Internet]. Seoul, Korea: National Statistics Office; c2012 [cited at 2012 Dec 5]. Available from: http://www.kcc. go.kr/user.do mode $=$ view $\&$ page $=\mathrm{P} 02050303 \& \mathrm{dc}=\mathrm{K} 020$ 50300\&boardId=1079\&boardSeq=25510.

23. Lee YT, Kim SY, Kang DW, Kwon AK, Ki YM, Kim MS, et al. Development of long-term strategies for u-Healthcare industry. Seoul, Korea: Korea Health Industry Development Institute; 2008. p. 25-194.
24. Kim JE, Kim SH, Jeong WC, Kim NS. Technical trend of USN sensor node. Electron Commun Trends 2007;22(3): 90-103.

25. Lee YT, Park JS. Analysis on current status of Korean u-Health services. Seoul, Korea: Korea Health Industry Development Institute; 2011. p. 147-50.

26. Park CY, Lim JH, Park SJ, Kim SH. Technical trend of uHealthcare standardization. Electron Commun Trends 2010;25(4):48-59.

27. Koh DY, Cho HS, Kang MS. Analysis on the demand for $\mathrm{u}$-health services and policy implications. Seoul, Korea: Korea Institute for Industrial Economics \& Trade; 2011. p. 80-200.

28. Choi JS, Yi BK, Park JH, Choi KS, Jung JG, Park SW, et al. The uses of the smartphone for doctors: an empirical study from Samsung Medical Center. Healthc Inform Res 2011;17(2):131-8.

29. Lee YT, Park JS, Lee KI. Analysis on the demand and supply system of u-Health workforce. Seoul, Korea: Korea Health Industry Development Institute; 2008. p. 6-20.

30. Lehoux P. Why examining the desirability of health technology matters. Healthc Policy 2008;3(3)29-39.

31. Song TM, Ryu SW, Lee SH. U-Health service for managing chronic disease: a case study on managing metabolic syndrome in a health center in South Korea. Healthc Inform Res 2011;17(4):260-6. 